\title{
Introduction
}

\section{Pseudo-Paracelsus: Forgery and Early Modern Alchemy, Medicine and Natural Philosophy}

\author{
Didier Kahn \\ CNRS, Cellf 16-18 - Sorbonne University \\ dkahn@msh-paris.fr \\ Hiro Hirai \\ The Italian Academy for Advanced Studies, Columbia University \\ hhirai2@gmail.com
}

Over the last 40 years, a number of major publications have considerably expanded our knowledge of the works of the Swiss physician Paracelsus (1493/941541) and his followers. As a result, Paracelsianism appears more clearly as a driving force in widening the horizons of alchemy by offering it a platform for more serious consideration than it had hitherto been afforded, and in exerting considerable influence on the shaping of modern biology and medicine in an environment of fierce scholarly controversies.

Despite much progress, there are still wide gaps in the research literature. The internal chronology of Paracelsus' works is not known in detail. Often, this led historians to deem his system static although closer study indicates that his ideas constantly evolved. The bulk of spurious works attributed to Paracelsus throughout the second half of the sixteenth century has made it even more difficult to establish an internal chronology, either for the authentic or inauthentic works.

The production of forgeries under Paracelsus' name was an integral part of the diffusion of Paracelsianism. Many of those forgeries were widely read and extremely influential, not only in the fields of medicine and "chymistry" (alchemy/chemistry), but also in cosmology, anthropology, theology and magic. For many cases, we know neither when exactly they were first attributed to Paracelsus, nor who their authors were, nor even how much they may derive from authentic works by Paracelsus. A whole strand of German Paracelsianism, although widely influential far beyond the German borders - extending to Central Europe, the Low Countries, France, England and Italy - is thus entirely 
out of our hands. Charles Webster in 1982 was amongst the first to remark upon the impact of Paracelsian forgeries on the formation of both Paracelsus' popular image and Paracelsianism. ${ }^{1}$

Paracelsian forgeries have yet to be studied in their own right. Discussing their content, sources, topics, potential authorship and composition dates will be beneficial on many levels. It will reveal their distinctive and common features, their mutual connections and their kinship, in style and content, with the genuine works of Paracelsus, thereby compelling scholars to renew their focus on the latter. These reciprocal consequences will result in a much sharper and more detailed knowledge both of Paracelsus himself and of Paracelsianism.

It is, of course, important to understand that most of these forgeries were considered authentic by early modern readers, who considered the works of Paracelsus as a whole without any further consideration into the chronological developments within the works. Although Johann Huser, the first editor of Paracelsus' complete philosophical and medical works (1589-1591), tried to differentiate between authentic and spurious treatises, this, along with the setting of a chronological order, only became a project seriously taken up by Karl Sudhoff between 1894 and 1933. Today's historians need this critical approach, in addition to an understanding of how early modern Paracelsians received the works now deemed spurious.

All these considerations have led us to conceive a wide-ranging, collective research project on both Paracelsus and pseudo-Paracelsus. A special panel on these topics was held in Boston at the annual meeting of the Renaissance Society of America in April 2016. Three months later, we organized another conference at Villa Vigoni (Italy) under the title: "Pseudo-Paracelsus: Alchemy and Forgery in Early Modern Medicine and Natural Philosophy." The papers collected here represent part of the results of this conference. ${ }^{2}$ In parallel, a digitization of the Huser edition of Paracelsus has been made available via the

1 Charles Webster, From Paracelsus to Newton. Magic and the Making of Modern Science (New York, 1996; 1st ed. 1982), 57. See also Charles D. Gunnoe, "Erastus and Paracelsianism: Theological Motifs in Thomas Erastus' Rejection of Paracelsian Natural Philosophy," in Allen G. Debus and Michael T. Walton, eds., Reading the Book of Nature: The Other Side of the Scientific Revolution (Kirksville, MO, 1998), 45-66, on 64 n. 64 .

2 Generous support for this project was provided by the Center for the History of Philosophy and Science, Radboud University (Nijmegen); Sorbonne University (Paris), ED III; the Cellf 16-18 (cNRS and Sorbonne University); the obvil (Sorbonne University); the Society for the History of Alchemy and Chemistry (London); Amadeo Murase and Seigakuin University (Tokyo); and Clare Hirai. 
online database THEO, engineered by Urs Leo Gantenbein (University of Zurich/Paracelsus Project). ${ }^{3}$

All papers in this special issue are arranged according to Paracelsian chronology. First, Dane T. Daniel examines the authenticity of two treatises of Paracelsus, the Brief an die Wittenberger Theologen (1525) and the Astronomia Magna (1537/1538). His attempt to establish criteria regarding their authenticity stresses the need to consider theological motifs whenever they are present in Paracelsian texts. Then Didier Kahn discusses one of the earliest spurious treatises ascribed to Paracelsus: the Philosophia ad Athenienses. First published in 1564 , this treatise is dominated by philosophical, cosmological and theological considerations. In the third article, Tobias Bulang focuses on one of the most interesting and lesser-known alchemical pseudo-Paracelsian treatises: the Aurora philosophorum (written before 1569), a main topic of which is the genealogy of knowledge since Adam. This treatise was hitherto known only through its abridged Latin translation by Gerhard Dorn (1577). Bulang presents the critical edition in progress of the still unpublished German text. Hiro Hirai then discusses the whole editorial context behind the first publication of the famous De natura rerum (1572), one of the richest and most complex treatises of the pseudo-Paracelsian corpus. This contextualization shows how De natura rerum emerged at the crest of a wave of publications of spurious works. The next article, by Charles D. Gunnoe, compares theories of plague in the authentic plague treatises of Paracelsus and in De pestilitate, an interesting and elusive spurious text written prior to 1578 and first published in the Huser edition in 1589. In all these plague treatises, plague is associated closely with magic and imagination.

With Martin Žemla, we return to the field of theological works: Žemla discusses two spurious works, in fact written by Adam Haslmayr, published in the collection of Paracelsian and Weigelian treatises Philosophia mystica (1618): Astronomia Olympi novi and Theologia Cabalistica. This important collection helped underline the significance of Paracelsus's theological ideas. By combining his theology with alchemy and the idea of universal reform, it fit well with the ethos of the early Rosicrucian manifestos. Finally, Lawrence M. Principe gives a detailed description of the gradual formation of the alchemical corpus attributed to the fictitious Basilius Valentinus between 1599 and 1717, including a biography for its supposed author. Due to its connection with Paracelsian

$3<$ <ww.paracelsus-project.org > accessed 31 October 2019. The digitization has been generously funded by the Theophrastus Stiftung. 
ideas, the Valentine corpus can be viewed, in Principe's words, as "an ancillary part of the pseudo-Paracelsian literature."

This collection of papers will certainly contribute to an advanced understanding of both Paracelsus and Paracelsianism. We hope it inspires other scholars to join our ongoing project. 